\title{
IoT-Based Framework for Smart Agriculture
}

\author{
Jian Yang, Jiangsu Vocational College of Agriculture and Forestry, China \\ Amit Sharma, Jaypee University of Information Technology, India \\ Rajeev Kumar, Chitkara University Institute of Engineering and Technology, Chitkara University, India \\ (iD) https://orcid.org/0000-0001-7189-3836
}

\begin{abstract}
Agriculture plays an important role in the making and development of a country. In India, agriculture is the primary source of living for more than about $60 \%$ of its population. The agriculture-related issues always hinder the development of a country. The enhancement of traditional agriculture methods and its modernization towards smart agriculture is the only solution for agriculture problems. Hence, by considering this issue, a framework is presented for smart agriculture using sensor network and IoT. The key features of this system are the deployment of smart sensors for the collection of data, cloud-based analysis, and decision based on monitoring for spraying and weeding. The smart farming approach provides valuable collection of data, high precision control, and automated monitoring approach. The proposed system presents smart agriculture monitoring system that collects and monitors the soil moisture, environmental temperature, and humidity. The measured soil moisture, temperature, and humidity are stored in ThingSpeak cloud for analysis.
\end{abstract}

\section{KEYWORDS}

Internet of Things (IoT), Precision Agriculture, Productivity, ThingSpeak Cloud Platform, Wireless Sensor Networks (WSNs)

\section{INTRODUCTION}

Precision agriculture is a method in which farmers optimize inputs such as water and fertilizer for the enhancement of productivity, quality and yield (Srbinovska et al., 2015). The term precision agriculture also encourages for minimizing pests and diseases through specially target application of precise amount of pesticides. Smart agriculture or precision agriculture is an integrated farm management framework which constitutes a holistic management approach aiming to optimize the yield per unit of farming land. Increasing the quantity and quality of agricultural products while utilizing less inputs such as fertilizers, water, pesticides, energy, etc., results in cost reduction with positive environmental impact (Mekala and Viswanathan, 2017). Therefore, rather than applying the same amount of fertilizers over the entire agricultural field or applying fertilizers to specially target area helps in overall cost reduction. The smart agriculture solution measures the variation in field conditions and adapts the fertilization or feed strategy accordingly (TongKe, 2013). Farmers as the principal stakeholders usually make complex decisions without proper information and execute the 
demanding field operations. Therefore, smart agriculture solutions are best designed considering farmers at the center of the process. The solutions of smart agriculture complements and transforms the skills and experiences gained naturally through the generations (Chhetri et al., 2017). The smart solution can complement the farmer's capabilities in three main processes. The three sub-processes are presented in Figure 1. The sub-processes are data collection, decision making, and intervention. The data collection is a part where remote sensing and sensor networks are utilized. In the decision making part, expert systems and machine learning can be exploited. The third part is an intervention where intelligent machinery and robotic agents can be utilized for field operations. The complete typical process cycle includes data collection for measuring such as soil moisture, temperature, $\mathrm{PH}$, humidity, or multi-spectral images. The data collection process is followed by the data analysis which produces a description for the pesticides, irrigation, fertilizers, and harvest. The last component of the process is an automated intervention which executes the description maps on the field area using variable rate technology machinery. This cycle can monitors the possible areas of concern like soil, vegetation, or the environment. In addition to this farmer, related sub-processes smart agriculture can be designed to provide extra benefits. The benefits for external functions such as soil and environment monitoring, traceability of food, and specific bookkeeping facilitating national planning (Mekala and Viswanathan, 2017). The recent survey presents the decreasing level of waters and drying up of major water resources such as rivers and tanks, presents efficient utilization of water resources (Veena et al., 2018). The technological evolution of WSNs and IoT made it possible to monitor the environment and agricultural fields for gaining the production (Khanna and Kaur, 2019).

These technologies are in different levels of maturity and adoption across all over the world. Therefore, more than often technology introduction to different communities needs to be planned and driven by the relevant authorities. The blind technology or solutions should account for the wide diversity of agriculture for the following characteristics particularly farm size, farming types, farming practices, level of yield, and employment (Patil and Kale, 2016). These are the major challenges in the technology of smart agriculture. The technology and their solutions should be customized and adapted accordingly. In general, the factors that affect technology adoption in agriculture are yield gap, farm size, and the learning required for the integration of new technologies with the existing practices (Elijah el al., 2018). On the other hand, smart agriculture solutions affect farming economics through multiple channels. Hence solution design should evaluate farming economics in different levels of analysis. The smart agriculture solution can reduce operational costs by optimizing the user inputs.

Figure 1. Sub-processes of Smart Agriculture

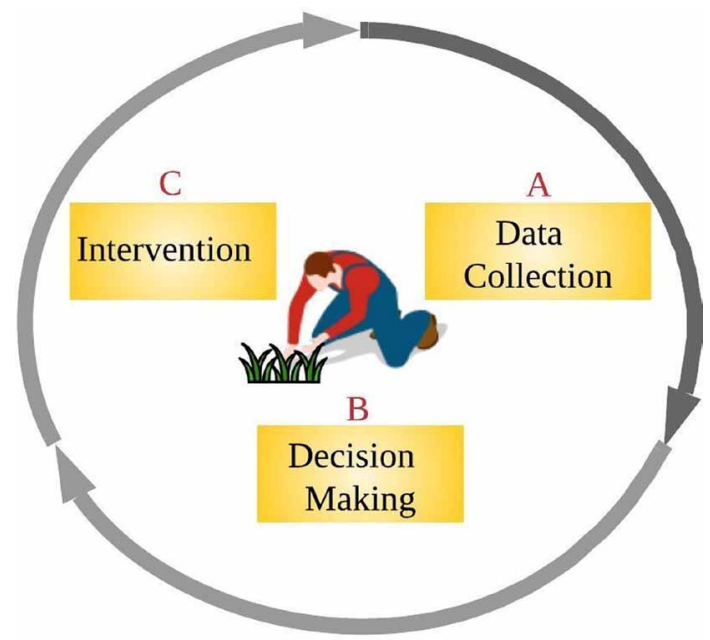


Even if the operational cost is increased under precision agriculture, yields can grow enough to increase the operating benefit. The smart agriculture solutions are built on the several enabling technologies involving sensor technology, global navigation satellite system (used for positioning), remote sensing, data storage and analysis, variable rate technology, advisory systems and interconnected communications, autonomous navigation and intelligent machinery (Lakshmisudha et al., 2016). Some of these technologies recently presented relatively high investments and adoption rates. The main idea is the design a system that can collect data in real-time from deployed sensors, analysis of data based on cloud platform and decision based on monitoring for spraying and weeding. The proposed system collects and monitors the soil moisture, environmental temperature and humidity. The control station processes the collected information for the decision making without human intervention. The measured soil moisture, temperature and humidity are stored in ThingSpeak cloud for analysis.

The remaining manuscript is organized as follows: Section 2 provides the related works on precision agriculture and smart agriculture based on IoT and cloud systems. Section 3 discusses the system design and the operational layers of the proposed model. Section 4 presents the experimental setup and the hardware/software used for the experimentation. The observed results and analysis are discussed in section 5 followed by the conclusion of the framework in section 6 .

\section{RELATED WORK}

The major rising issues of agriculture such as decreasing water levels (rivers and tanks) and environmental factors that need to be addressed and requires a solution based on smart agriculture. (Liqiang et al., 2011) presented a system for monitoring crops utilizing temperature and moisture sensors. (Ocampo et al., 2017) developed an algorithm based on temperature and soil moisture values and the sensed information is processed through the gateway for controlling water quantity. Their proposed system has duplex communication links and power through photovoltaic panels. Their system utilizes a cellular network interface for data transmission and its calculations for irrigation scheduling. The advancement in the field of wireless sensor networks has helped the evolution of many approaches for precision agriculture applications. (Chaudhary et al., 2011) have presented a system that utilizes WSNs for monitoring and controlling greenhouse parameters. It is observed from the study of different agriculture fields that outcomes from agriculture are decreasing day by day. The adoption of new technologies for precision agriculture promises an increase in production rate and also reduces the extra manpower requirements. There exist many studies contributing to the benefit of farmers which provides an efficient system based on new technologies for increasing the overall production rates (Varman et al., 2017). (Keshtgari and Deljoo, 2011) developed a system that uses a distributed wireless sensor networks system. Their proposed system is designed for providing realtime monitoring of the agriculture field and controlled irrigation scheme for increasing productivity utilizing water resources efficiently. The system provides the design in detail including real-time field sensing and controlled irrigation utilizing the software. The designed system provides a lowcost efficient solution for irrigation control using WSNs. The system using WSNs for precision agriculture highly depends on the field parameters such as soil moisture, temperature, and humidity levels. Sensor nodes were deployed below the soil for the collection of parameters and these sensor communicates among others using communication protocols and transmits their measured data to the control station through the sink node. (Zhao et al., 2017) have designed a communication protocol for quick transmission of the sensor data to the sink node. Their proposed design delivers very few duty cycles and results increase in the lifetime of the monitoring system. (Bachuwar et al., 2018) have developed a system that utilizes sensors and UART (universal asynchronous receiver transmitter) interface. The transmission is carried out through hourly sampling, buffering of data, its transmission, and at last the validation of status. The experimental results present attenuation in radio frequency signals because of sensor deployment under the soil and the deployment cost is comparatively high. (Gayatri et al., 2015) presents a solution for monitoring agricultural fields along with the irrigation 
control utilizing GPS (global positioning system) enable sensors. Their system is capable for providing timely response but the drawback is deployment cost and the attenuation which caused by deploying sensors under soil. (Dan et al., 2015) presented a greenhouse monitoring system based on WSNs and IoT integration with cloud. Their system is capable of logging and storing data in cloud periodically and present an effective solution for greenhouse monitoring.

(Heble et al., 2018) have presented a cost-effective solution of farming where the water resources are limited. The designed system considers low-cost sensors and easy circuitry and designed an automatic water flow control system. The real-time monitoring considers sensing of temperature and humidity and displaying them on LCD. Their designed system provides the water efficiently to the needed plants measured according to the present moisture level. (Reche et al., 2014) have proposed an irrigation scheduler system based on low cost and time-dependent microcontroller. Their designed system comprises of sensor network for the detection of soil moisture and temperature levels. The real-time sensed data is processed to the users through SMS using GSM module.

(Nawandar and Satpute, 2019) presented an irrigation system consists of soil moisture sensors and irrigation controllers. Their system provides a wireless link among the farmer computer and irrigation controller. The designed system can be adopted where the water quality is poor or limited. They have implemented a decision support system for the optimization of irrigation control, the use of fertilizers, and water for the development of crops. (Channe et al., 2015) designed a smart agriculture system based on cloud computing and the Internet of Things. The cloud platform is utilized for achieving load balancing and resource's dynamic distribution. (Rajeswari et al., 2017) presented a system based on the control network and IoT platform. Their design also presents an information management system for storing and processing data. The stored data can be accessed to facilitate various researches on agriculture. Table 1, presents the comparative study of a conducted literature survey of different agriculture approaches. Most of the solutions provided for smart farming or precision agriculture does not provide a cost-effective solution for farming. The system for irrigation presented by (Reche et al., 2014) is the most efficient solution for smart agriculture as their approach provides the real time analysis of data. The designed model presents a cost-effective solution for smart agriculture. The proposed system measures the realtime field parameters and stores the data in a cloud platform for real-time analysis.

\section{SYSTEM DESIGN}

The prime objective behind our design is to present a smart agriculture system based on IoT and sensor network that can control the irrigation and fertilizers for high crop production. The system

Table 1. Comparative study of different agriculture approaches

\begin{tabular}{|c|c|c|c|c|c|}
\hline Reference & Keywords & $\begin{array}{c}\text { Smart } \\
\text { Devices }\end{array}$ & $\begin{array}{c}\text { Cloud System } \\
\text { Analysis }\end{array}$ & Future Storage & Microcontroller \\
\hline $\begin{array}{l}\text { (Liqiang et al., } \\
\text { 2011) }\end{array}$ & Soil Moisture & No & No & No & Nil \\
\hline $\begin{array}{c}\text { (Channe et al., } \\
\text { 2015) }\end{array}$ & $\begin{array}{c}\text { Soil Moisture, Temp., } \\
\text { Humidity }\end{array}$ & Yes & Yes & Yes & Arduino Uno \\
\hline $\begin{array}{c}\text { (Chaudhary et al., } \\
\text { 2011) }\end{array}$ & Soil Moisture, Temp. & Yes & No & Yes & PIC16F887 \\
\hline $\begin{array}{l}\text { (Reche et al., } \\
\text { 2014) }\end{array}$ & $\begin{array}{l}\text { Wind Speed, Soil } \\
\text { Moisture, Temp., } \\
\text { Humidity }\end{array}$ & Yes & Yes & Yes & $\begin{array}{l}\text { Irrigation } \\
\text { Controller }\end{array}$ \\
\hline $\begin{array}{l}\text { (Heble et al., } \\
\text { 2018) }\end{array}$ & $\begin{array}{l}\text { Temp. Soil Moisture, } \\
\text { Wind Speed }\end{array}$ & Yes & No & No & $\begin{array}{c}\text { PIC } \\
\text { Microcontroller }\end{array}$ \\
\hline
\end{tabular}


design requires soil moisture, temperature, humidity, and air monitoring sensors for designing a system without human interventions. Figure 2, presents the proposed framework for smart agriculture based on sensor networks and IoT. The proposed design consists of four layers of operation which are sensor deployment, middleware, communication, and application layer.

\subsection{Sensor Deployment Layer}

Sensor deployment in the agriculture field is the first layer of operation. The proposed system uses a soil moisture sensor, temperature, and humidity sensor and air monitoring sensor for the collection of field data. The deployed sensor nodes are presented in Figure 3. These sensor nodes are responsible for collecting real-time field data and regular monitoring of the agriculture field. The soil moisture sensor measures the soil moisture level, temperature, and humidity sensor to measure the relative temperature and humidity levels. Similarly, an air monitoring sensor is used to estimate wind speed and directions. These sensor nodes communicate with each other and transfer the sensed information to the sink or master node.

The sink node is Arduino Uno based microcontroller, which is responsible for collecting field data and transferring information further to the ThingSpeak cloud platform for storage and its analysis. The hardware used for the experimentation collects data in real time (soil moisture level, relative temperature $\&$ humidity and wind speed). The sensor nodes communicates with each other wirelessly and transfers sensed data to sink node which is GSM enabled. This sink node is responsible for gathering the field information and transferring data to the cloud for analysis and storing.

\subsection{Middleware Layer}

Middleware is the second operation layer of our proposed system. This layer is responsible for controlling the actuators and automating the agriculture process. The collected values beyond the threshold are transferred to the controller for their analysis in the ground station. These operational layers carefully monitor the soil moisture, temperature, humidity, and wind speed as these factors

Figure 2. loT based framework for smart agriculture

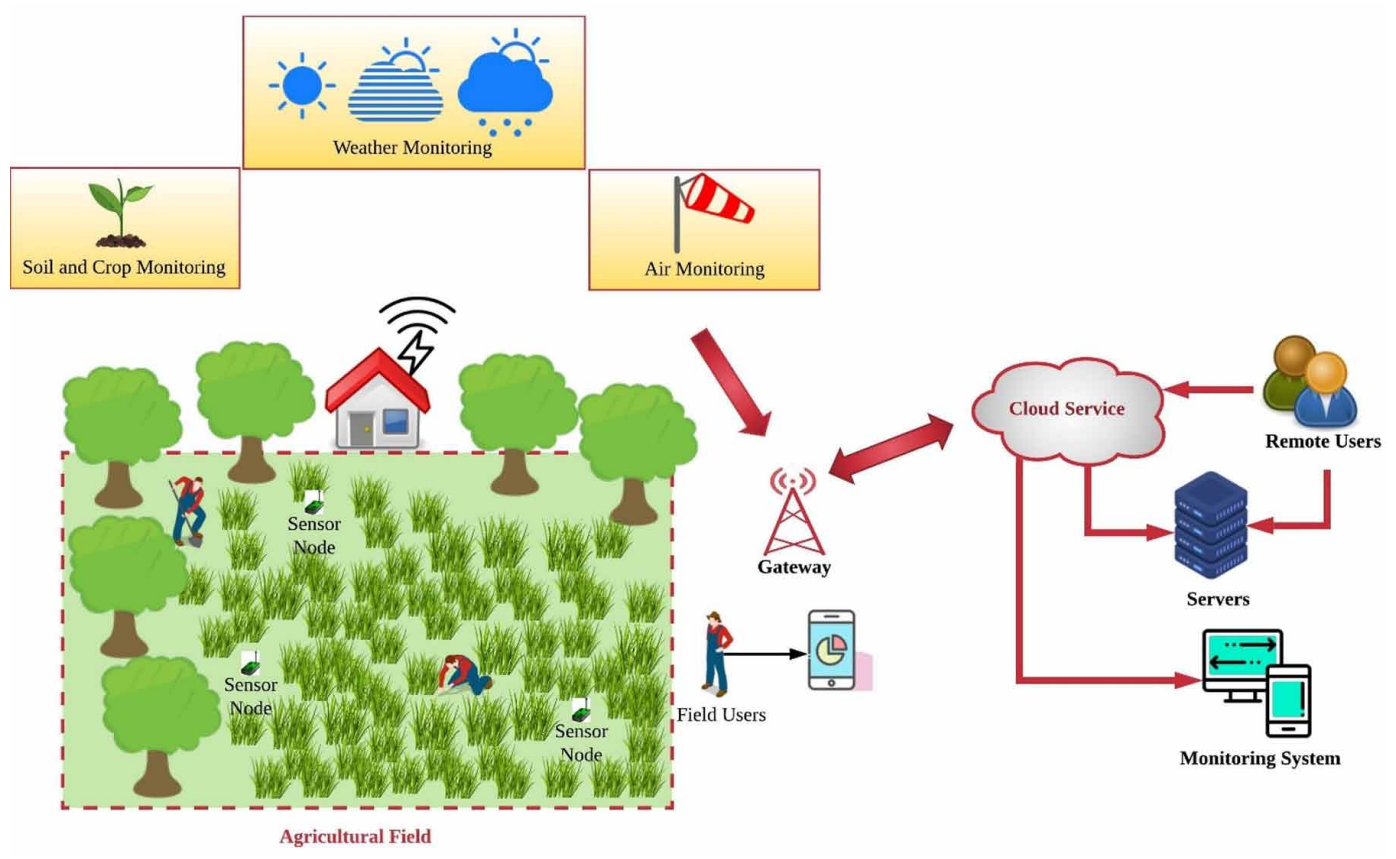


Figure 3. Deployment of Sensors for data collection

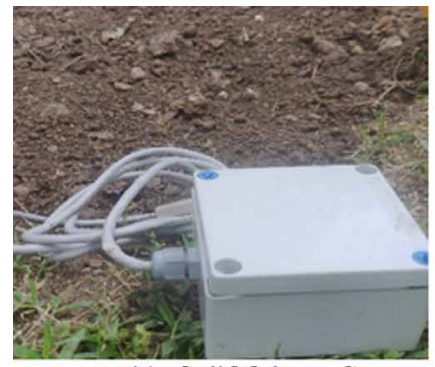

(a) Soil Moisture Sensor

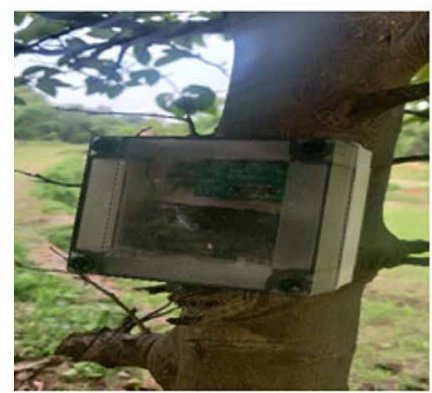

(c) Air Monitoring Sensor

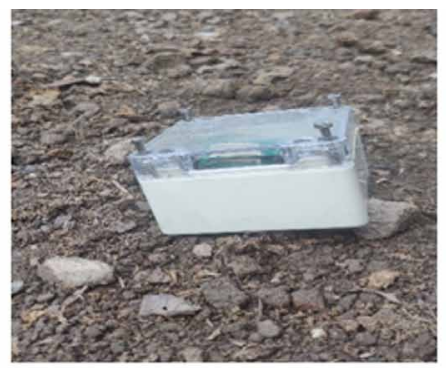

(b) Temp. and Humidity Sensor

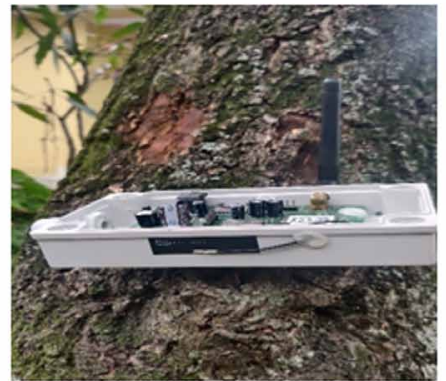

(d) Sink Node

directly impact agricultural yields. The system is configured considering three factors; in the first factor when the soil moisture is observed below its threshold value an alert message is generated and send to the user through e-mail. The automated system then generates a query for turning $\mathrm{ON}$ the water motor for soil irrigation. When the required irrigation level is covered the system automatically turns OFF the water motor. The factor considers the rise in relative temperature and humidity values beyond the threshold. The system sends an automated generated alert and suggests to open the flap of greenhouse or poly-house for maintaining the ambient atmosphere. The third factor is the wind speed and its direction which is monitored by air monitoring sensors. When air monitoring value succeeds threshold, systems generate an alert for covering the region and targeted plants, protecting them from harm. The middleware layer is responsible for above mentioned three operations. These operations are carried out in the ground station using the ThnigSpeak platform based on the realtime analysis of sensed field data. Controlling these three factors in the targeted agriculture region, increase the overall crop production with efficient use of resources.

\subsection{Communication and Cloud Analysis Layer}

The third operational layer of the proposed system is the communication layer. This layer uses Ardunio Uno based microcontroller and responsible for communicating with the deployed sensors. The collected data is transferred to the base station through this gateway wirelessly as it is comprised of the GSM module. This module is WiFi-enabled and communicates the information wirelessly. The deployed sensor monitors the field data such as moisture, temperature, humidity, wind speed, and communicates them to the gateway node. An IP protocol is running in the controller gateway which sends the collected information to ThingSpeak cloud for analysis and making decisions.

\subsection{Application Layer}

The advancement in the field of cloud computing and edge computing provides an effective solution for the issues of smart agriculture application. The designed model uses the ThingSpeak cloud platform for the collection of field data and provides efficient storage and analysis. In this operational layer, 
various channels are created for specific field parameters that represent their regular monitoring and storing of data fields with time and date. The gateway node transmits the particular measured data to their respective channels. Table 2 represents the sample of an observed dataset from the agricultural field in the Thing Speak Platform. In table 2 column 1 represents the time and date of recorded instance, column 2 represents their entry numbers. The rest of columns represents values of soil moisture in percentage (amount of water present in soil), temperature (in degree Celsius), humidity in percentage (amount of moisture present in air) and wind speed (in meters per second). The data is analyzed using MATLAB in ThingSpeak cloud for calculating irregularities and predicting the results. These data values are plotted using MATLAB for its time-based analysis in the ground station. The agricultural field data can be monitored from anywhere at any time, remotely using web service.

\section{EXPERIMENTAL SETUP}

The performance of the system is realized by deploying sensor modules in the agriculture field and analyzing real-time collected in ThingSpeak IoT Platform. The hardware setup consists of Arduino Uno and other various sensors for collecting field data. The hardware and software utilized for experimentation are discussed below and presented in Figure 3.

\subsection{Hardware Used}

\section{Arduino Uno Microcontroller}

Atmega 8- bit, low power microcontroller is used and it provides $8 \mathrm{~K}$ bytes of flash memory which is self-programmable. The microcontroller supports 23 programmable input output ports and 10 bit of analog to digital converter.

\section{Soil Moisture Sensor}

The soil moisture sensor is deployed for calculating the percentage of water quantity present in the soil. The required average percentage of the water content in soil varies for different agriculture domains

Table 2. Sample of observed data from the agricultural field in ThingSpeak Platform

\begin{tabular}{|c|c|c|c|c|c|}
\hline Recorded Instances & $\begin{array}{c}\text { Entry } \\
\text { No. }\end{array}$ & Soil Moisture (\%) & $\begin{array}{c}\text { Temperature } \\
\left({ }^{\circ} \mathbf{C}\right)\end{array}$ & $\begin{array}{c}\text { Humidity } \\
(\%)\end{array}$ & $\begin{array}{c}\text { Wind Speed } \\
(\mathbf{m} / \mathbf{s})\end{array}$ \\
\hline $\begin{array}{c}2020-03-1510: 15: 23 \\
+0530\end{array}$ & 81 & 24 & 18.21 & 65 & 5.5 \\
\hline $\begin{array}{c}2020-03-1510: 19: 51 \\
+0530\end{array}$ & 82 & 26 & 18.26 & 68 & 4.2 \\
\hline $\begin{array}{c}2020-03-1510: 24: 45 \\
+0530\end{array}$ & 83 & 25 & 19.14 & 67 & 3.9 \\
\hline $\begin{array}{c}2020-03-1510: 28: 40 \\
+0530\end{array}$ & 84 & 28 & 19.02 & 65 & 5.3 \\
\hline $\begin{array}{c}2020-03-1510: 32: 24 \\
+0530\end{array}$ & 85 & 30 & 19.05 & 63 & 5.2 \\
\hline $\begin{array}{c}2020-03-1510: 36: 20 \\
+0530\end{array}$ & 86 & 28 & 20.03 & 69 & 5.0 \\
\hline $\begin{array}{c}2020-03-1510: 39: 53 \\
+0530\end{array}$ & 87 & 29 & 19.07 & 68 & 5.6 \\
\hline $\begin{array}{c}2020-03-1510: 43: 06 \\
+0530\end{array}$ & 88 & 28 & & 69 & \\
\hline
\end{tabular}


and it may vary considering various environmental factors. The moisture sensor is used to measure the percentage of water in the soil and to transfer the collected measurement to the controller for making control actions in terms of turning On/Off Water motors. The soil moisture sensor consists of two attached electrodes that need to be placed in the upper layer of soil. The soil moisture sensor is an analog sensor and it provides an analog output to the controller. The output of the moisture sensor is converted to a digital value (10 bit) and hence the average percentage is calculated.

\section{Temperature and Humidity Sensor}

Various crops are evolved as temperature and humidity sensitive. DHT11 a digital sensor is utilized for measuring temperature and humidity values. This sensor provides the early detection of temperature and humidity values so that some precautionary steps or preparations can be implemented for the upcoming season to increase crop production. The temperature and humidity values play an important role in deciding the accurate cultivating time of crops.

\section{Air Monitoring Sensor}

Fresh air is very much important for the nourishment of crops and plants. The amount of polluted air may degrade the growth or may sick crops and plants. Therefore, the monitoring of air quality is an important parameter for the growth of plants and crops. MQ135 air monitoring sensor is used which provides an analog output. This sensor detects the wind speed and the presence of toxic gases in the air. The output in the form of analog is converted to 10-bit digital form and then presented in percentage.

\section{Raspberry Pi}

Raspberry Pi provides the sensor interface to the gateway node and performs computing and networking operations. It is the most important part of the Internet of Things platform. It provides the wireless transmission of sensed information to the cloud so that the data can be accessed remotely. The Pi model B is utilized for this framework which has a quad-core ARM processor, HDMI and USB ports, GSM module and storage SD slot.

\subsection{Software Used}

\section{ThingSpeak IoT Platform}

ThingSpeak Cloud platform is used for the real time analysis of ground data. This cloud platform provides the facilities for processing of data in case of any adversaries. An observed sample of ground data is presented in Table 2. It is used to plot the sensed information of field in terms of soil moisture, temperature, humidity and air quality.

\section{MATLAB Function}

MATLAB function of ThingSpeak platform is utilized for presenting the comparative study of previous and current stored values. The observed data can be analysed implementing various machine learning and deep learning algorithms for their evaluation.

\section{RESULTS AND ANALYSIS}

ThingSpeak IoT platform provides services such as data aggregation, visualization, and data analysis of live streams. The sensed field information is transmitted to the cloud platform using gateway module and instant visualization of data is created and alerts are generated and transmitted using web service. The MATLAB analysis of ThingSpeak stored data, runs a MATLAB code for processing, visualizing, and analyzing data streams. Based on experimental setup the proposed system collects real-time field information such as soil moisture, temperature, humidity, and wind speed. These sensed instances are transmitted to the cloud system for their timely analysis. The sensed information is plotted in 
the ThingSpeak IoT platform every 3 to 6 minutes of delay. Figure 4, presents the generated plots from following sensed data (a): Soil Moisture, (b): Temperature, (c): Humidity and (d): Air quality. The cloud platform represents the graphical representation of sensed agricultural field data. The field information is visualized in real-time utilizing cloud applications. It is observed from Figure 4 , that the field data is updated and plotted through ThingSpeak analysis. The graph represents the variation in the sensed values in different instances and plotted accordingly. Field 1 is set for soil moisture channel, field 2 corresponds to temperature channel, field 3 for humidity, and field 4 for air quality measurement. The different fields update their data and stores every upcoming value every 3 to 6 minutes.

The MATLAB function of the ThingSpeak platform is utilized and a MATLAB code is executed for the visualization of temperature comparison for three days and to find the relation between the relative temperature and wind speed. Figure 5, presents the MATLAB based visualization of three days measured values of temperature and relative temperature values with wind speed. This visualization helps in predicting the upcoming weather for considering changes and implementing operations for improving crop production. In agriculture, the efficient use of water is an important factor. This system mainly focuses on the effective utilization of water in agriculture along with the weather prediction. The work is mainly based on the moisture content of the soil, and relative temperature and humidity values. This system allows a sufficient supply of water to the agriculture field and accurate prediction of weather for increasing the crop yields.

The prediction of upcoming weather plays an important role in maximizing crop yields. The proposed system based on the MATLAB analysis of recently recorded temperature values of three days predicts the weather report. Figure 6, presents the histogram of temperature variation at different temperature ranges. The weather prediction is calculated using the MATLAB analysis of recorded temperature values.

Figure 4. Generated plots from observed data in ThingSpeak cloud application for (a) soil moisture, (b) temperature, (c) humidity and (d) air quality

Field 1

IOT BASED SMART AGRICULTURE SYSTEM

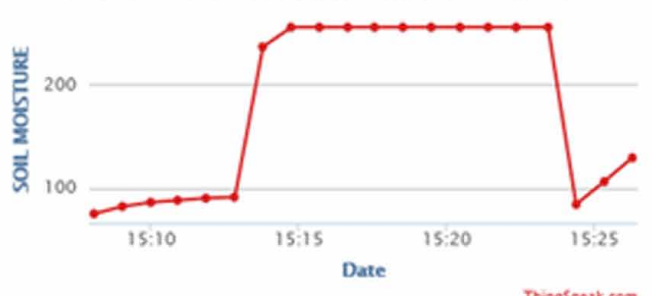

(a)

Field 3

IOT BASED SMART AGRICULTURE

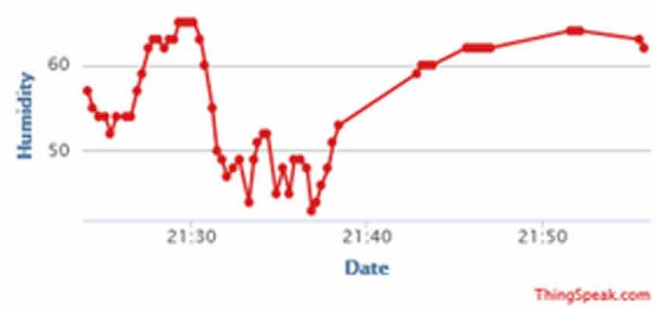

(c)
Field 2

IOT BASED SMART AGRICULTURE SYSTEM

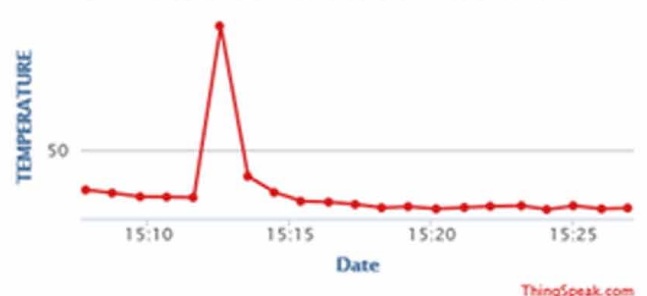

(b)

Field 4

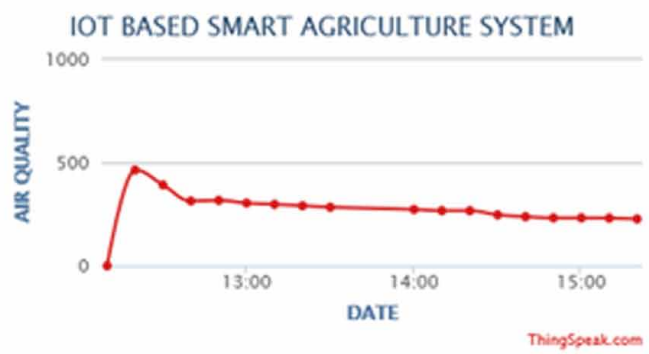

(d) 
Figure 5. Temperature comparison for recent three days and relation between temperature and wind speed
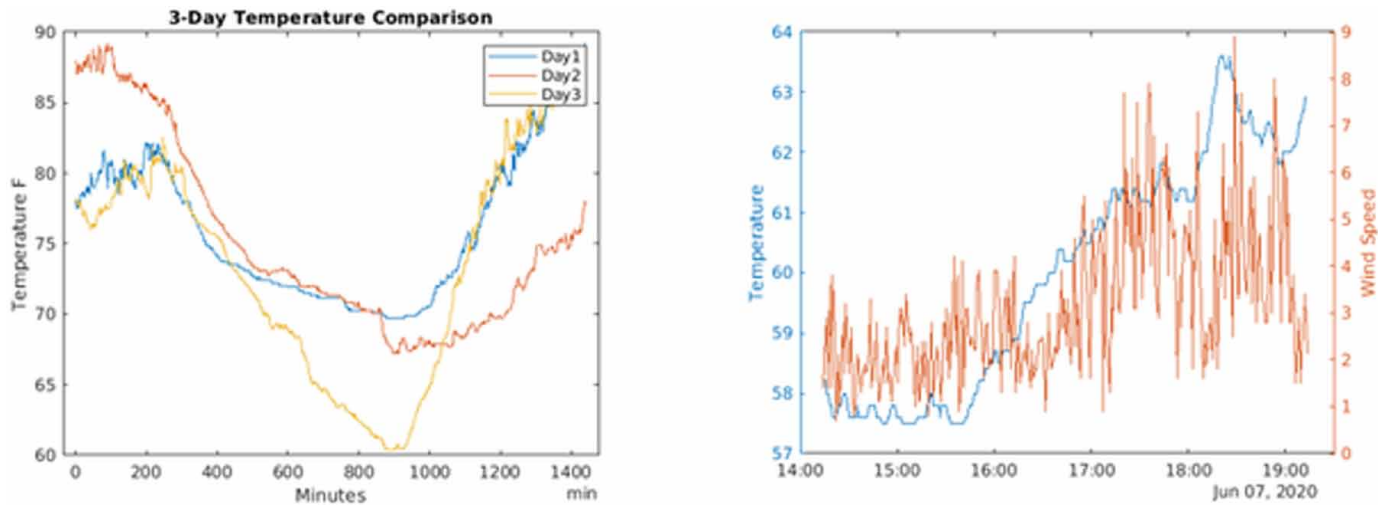

Figure 6. Number of measured temperature instances at different temperature ranges

Histogram of Temperature Variation

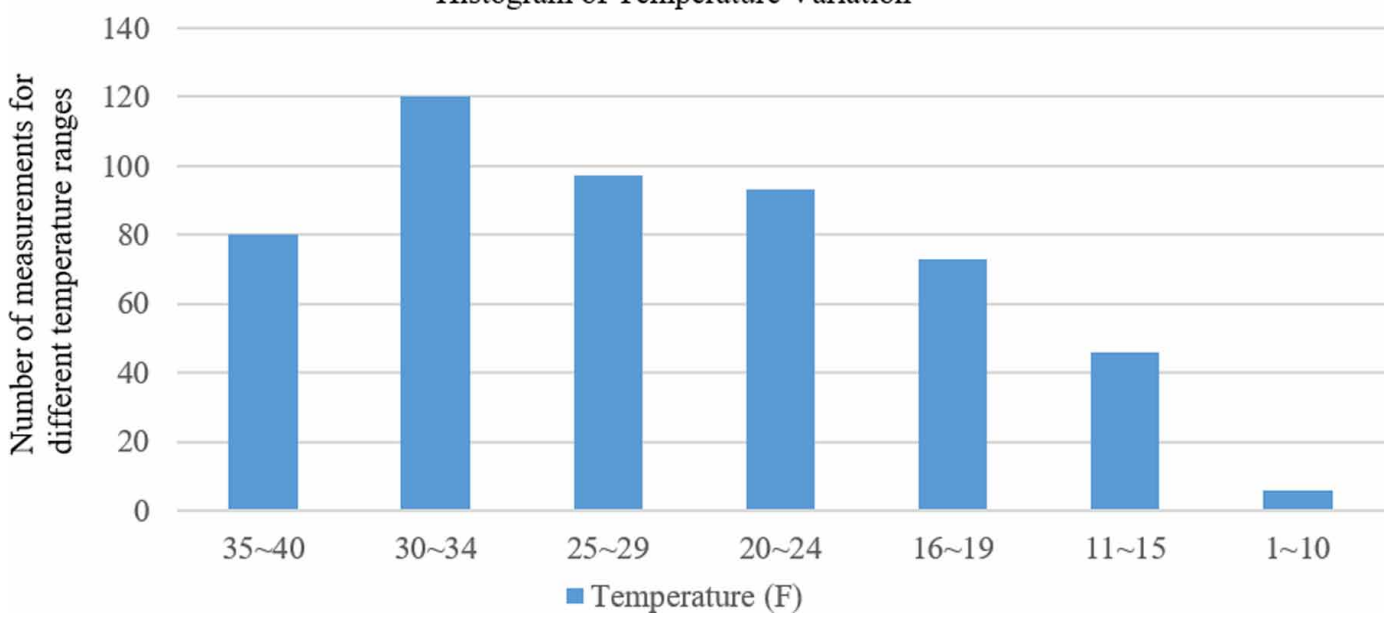

The temperature is monitored for predicting the weather condition and this further helps in predicting the percentage of moisture content in soil for the coming days. Weather prediction helps in calculating the percentage of dryness that may occur in the agriculture field. The system updates the user through notification whenever the soil is in dry condition means high resistance. Based on the threshold values of moisture sensor an automatic operation of soil irrigation through water motor is initiated.

The soil moisture content varies for different types of agricultural fields. The designed system is capable of pumping water to the field whenever required. The automated operation of the water motor turns off automatically when the percentage wet level of the soil is achieved. Figure 7 presents the resulted graphs of the proposed system where (a) represents the recorded temperature of the recent three days and (b) represents the operational time of water motor to make the soil wet.

After the execution of MATLAB code, the readings of soil moisture content, temperature, and humidity, air quality can be visualized through the ThingSpeak platform. The system sends alerts of moisture, temperature, and humidity values through emails to the field users. Based on the abovementioned experimental set up different instances of soil moisture, temperature, humidity, and air quality are monitored and analyzed using a cloud platform. The automated operation of the system 
Figure 7. Result visualization, (a) recent recorded temperature for three days and (b) irrigation operation in the field till $100 \%$ wetness of soil

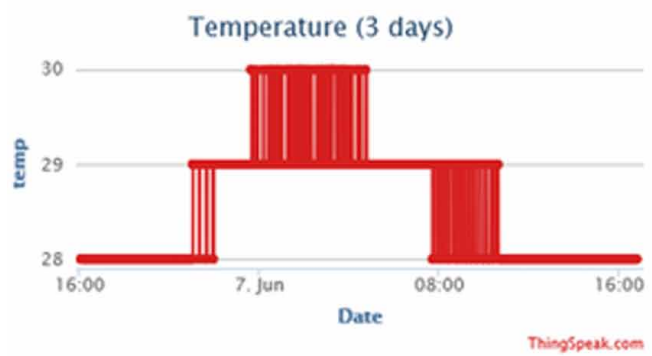

(a)
IOT BASED SMART AGRICULTURE SYSTEM

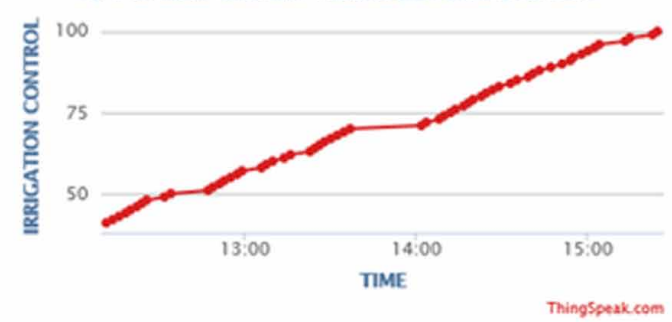

(b)

controls the irrigation equipment without the intervention of humans. The system is capable of providing continuous monitoring of the agricultural field and triggers the operation of the motor as per the requirement. The performance of the system is evaluated considering two major performance metrics. Average response time and standard deviation at the same cloud platform and different cloud platforms. The response time and standard deviation are measured for the same clod platform and different cloud platforms for the evaluation of the overall system's performance.

Table 3, presents the analysis of the proposed framework for average response time and standard deviation at the same cloud and different cloud platforms. The observed standard deviation and response time of the system for the same clout platform are 10.63 milliseconds and 13.57 milliseconds. Similarly, for different cloud systems, the standard deviation and response time are recorded as 16.24 milliseconds and 25.17 milliseconds. These observed results are compared with other cloud-based approaches (Reche et al., 2014; Nawandar and Satpute, 2019) and it is analyzed that the performance of the proposed framework is better than others and concludes that the system is efficient for continuous monitoring of agricultural fields.

\section{CONCLUSION}

In this paper, a framework for agricultural field monitoring and irrigation control is proposed using the concept of IoT. Internet of Things provides an efficient solution for smart agriculture and proves its importance for helping farmers by increasing the overall productivity. This framework is designed using sensor networks and cloud platforms for storing and analyzing data in real-time. The system senses different field information like soil moisture, temperature, humidity, and air quality and transmits this information to the cloud using a gateway. The cloud platform is responsible for storing data and performing data aggregation, analyses, and visualization tasks. Based on the sensed

Table 3. Performance analysis of the proposed system for average response time and standard deviation

\begin{tabular}{|c|c|c|c|c|c|c|}
\hline \multirow{2}{*}{$\begin{array}{c}\text { Performance } \\
\text { Metrics }\end{array}$} & \multicolumn{3}{|c|}{ Same Platform } & \multicolumn{3}{c|}{ Different Platform } \\
\cline { 2 - 7 } & CloudMQTT & M2M & Proposed & CloudMQTT & M2M & Proposed \\
\cline { 2 - 7 } & 25.64 & 18.36 & 13.57 & 45.26 & 28.45 & 25.17 \\
\hline $\begin{array}{c}\text { Response Time } \\
\text { (ms) }\end{array}$ & 18.32 & 13.24 & 10.63 & 30.14 & 20.65 & 16.24 \\
\hline $\begin{array}{c}\text { Standard } \\
\text { Deviation (ms) }\end{array}$ & & & & & & \\
\hline
\end{tabular}


information system predict the upcoming weather and amount of dryness present in the soil. The system schedules the irrigation process based on the real-time collected data and weather prediction. This system generates alerts that suggest farmers or users whether soil irrigation is required or not along with the percentage of soil moisture content. The experiments and observations prove that the proposed system is an efficient solution for real-time monitoring and irrigation issues. The implementation of this system is the agricultural field can benefits users by improving crop yields and production rates. The work can be extended for diagnosing crop diseases, insects, and weeds that occur in crops. Artificial neural network and image processing can be adopted for the detection and diagnosis of crop diseases by installing digital cameras in the agricultural field.

\section{ACKNOWLEDGMENT}

Key project of Jiangsu Education Science " $13^{\text {th }}$ five year plan": phased achievements in the construction and research of Internet of Things application technology from the perspective of Sydney agreement, Project No.: B-a/2018/03/08. 


\section{REFERENCES}

Bachuwar, V. D., Shligram, A. D., \& Deshmukh, L. P. (2018). Monitoring the soil parameters using IoT and Android based application for smart agriculture. In AIP Conference Proceedings (Vol. 1989, No. 1). AIP Publishing LLC. doi:10.1063/1.5047679

Channe, H., Kothari, S., \& Kadam, D. (2015). Multidisciplinary model for smart agriculture using internet-ofthings (IoT), sensors, cloud-computing, mobile-computing \& big-data analysis. Int. J. Computer Technology and Application, 6(3), 374-382.

Chaudhary, D. D., Nayse, S. P., \& Waghmare, L. M. (2011). Application of wireless sensor networks for greenhouse parameter control in precision agriculture. International Journal of Wireless \& Mobile Networks, 3(1), 140-149. doi:10.5121/ijwmn.2011.3113

Dan, L. I. U., Xin, C., Chongwei, H., \& Liangliang, J. (2015). Intelligent agriculture greenhouse environment monitoring system based on IOT technology. In 2015 International Conference on Intelligent Transportation, Big Data and Smart City (pp. 487-490). IEEE. doi:10.1109/ICITBS.2015.126

de Ocampo, A. L. P., \& Dadios, E. P. (2017). Energy cost optimization in irrigation system of smart farm by using genetic algorithm. In 2017IEEE 9th International Conference on Humanoid, Nanotechnology, Information Technology, Communication and Control, Environment and Management (HNICEM) (pp. 1-7). IEEE. doi:10.1109/HNICEM.2017.8269497

Elijah, O., Rahman, T. A., Orikumhi, I., Leow, C. Y., \& Hindia, M. N. (2018). An overview of Internet of Things (IoT) and data analytics in agriculture: Benefits and challenges. IEEE Internet of Things Journal, 5(5), 3758-3773. doi:10.1109/JIOT.2018.2844296

Gayatri, M. K., Jayasakthi, J., \& Mala, G. A. (2015). Providing Smart Agricultural solutions to farmers for better yielding using IoT. In 2015 IEEE Technological Innovation in ICT for Agriculture and Rural Development (TIAR). IEEE.

Heble, S., Kumar, A., Prasad, K. V. D., Samirana, S., Rajalakshmi, P., \& Desai, U. B. (2018). A low power IoT network for smart agriculture. In 2018 IEEE 4th World Forum on Internet of Things (WF-IoT) (pp. 609-614). IEEE. doi:10.1109/WF-IoT.2018.8355152

Keshtgari, M., \& Deljoo, A. (2011). A wireless sensor network solution for precision agriculture based on zigbee technology. Academic Press.

Khanna, A., \& Kaur, S. (2019). Evolution of Internet of Things (IoT) and its significant impact in the field of Precision Agriculture. Computers and Electronics in Agriculture, 157, 218-231. doi:10.1016/j. compag.2018.12.039

Khatri-Chhetri, A., Aggarwal, P. K., Joshi, P. K., \& Vyas, S. (2017). Farmers' prioritization of climate-smart agriculture (CSA) technologies. Agricultural Systems, 151, 184-191. doi:10.1016/j.agsy.2016.10.005

Lakshmisudha, K., Hegde, S., Kale, N., \& Iyer, S. (2016). Smart precision based agriculture using sensors. International Journal of Computers and Applications, 146(11), 36-38. doi:10.5120/ijca2016910916

Liqiang, Z., Shouyi, Y., Leibo, L., Zhen, Z., \& Shaojun, W. (2011). A crop monitoring system based on wireless sensor network. Procedia Environmental Sciences, 11, 558-565. doi:10.1016/j.proenv.2011.12.088

Mekala, M. S., \& Viswanathan, P. (2017). A novel technology for smart agriculture based on IoT with cloud computing. In 2017 International Conference on I-SMAC (IoT in Social, Mobile, Analytics and Cloud) $(I-S M A C)$ (pp. 75-82). IEEE. doi:10.1109/I-SMAC.2017.8058280

Mekala, M. S., \& Viswanathan, P. A. (2017). Survey: Smart agriculture IoT with cloud computing. In 2017 international conference on microelectronic devices, circuits and systems (ICMDCS). IEEE.

Nawandar, N. K., \& Satpute, V. R. (2019). IoT based low cost and intelligent module for smart irrigation system. Computers and Electronics in Agriculture, 162, 979-990. doi:10.1016/j.compag.2019.05.027

Patil, K. A., \& Kale, N. R. (2016). A model for smart agriculture using IoT. In 2016 International Conference on Global Trends in Signal Processing, Information Computing and Communication (ICGTSPICC) (pp. 543-545). IEEE. doi:10.1109/ICGTSPICC.2016.7955360 
Rajeswari, S., Suthendran, K., \& Rajakumar, K. (2017). A smart agricultural model by integrating IoT, mobile and cloud-based big data analytics. In 2017 International Conference on Intelligent Computing and Control (I2C2) (pp. 1-5). IEEE. doi:10.1109/I2C2.2017.8321902

Reche, A., Sendra, S., Díaz, J. R., \& Lloret, J. (2014). A smart M2M deployment to control the agriculture irrigation. In International conference on ad-hoc networks and wireless (pp. 139-151). Springer.

Srbinovska, M., Gavrovski, C., Dimcev, V., Krkoleva, A., \& Borozan, V. (2015). Environmental parameters monitoring in precision agriculture using wireless sensor networks. Journal of Cleaner Production, 88, 297-307. doi:10.1016/j.jclepro.2014.04.036

TongKe. (2013). Smart agriculture based on cloud computing and IOT. Journal of Convergence Information Technology, 8(2).

Varman, S. A. M., Baskaran, A. R., Aravindh, S., \& Prabhu, E. (2017). Deep learning and IoT for smart agriculture using WSN. In 2017 IEEE International Conference on Computational Intelligence and Computing Research (ICCIC) (pp. 1-6). IEEE.

Veena, S., Mahesh, K., Rajesh, M., \& Salmon, S. (2018). The survey on smart agriculture using IOT. Int J Innov Res Eng Manag, 5(2), 63-66.

Zhao, W., Lin, S., Han, J., Xu, R., \& Hou, L. (2017). Design and implementation of smart irrigation system based on LoRa. In 2017 IEEE Globecom Workshops (GC Wkshps) (pp. 1-6). IEEE. doi:10.1109/ GLOCOMW.2017.8269115

Jian Yang is associated with Jiangsu Vocational College of Agriculture and Forestry and is having research interest in IoT. Rajeev Kumar working, as an Assistant Professor, at Chitkara University Institute of Engineering and Technology, Chitkara University, Punjab, India. He received his B. Tech. and M.Tech. Degrees in Electronics and Communication Engineering from Kurukshetra University, Kurukshetra, India, in 2008 and 2010 respectively and also completed his Ph.D. degree in Electronics Engineering from Banasthali University, Rajasthan, India, in 2017. His research interests include almost aspects of Antenna Design with special emphasis on Frequency reconfigurable antennas, Ultra-wide-band antenna, and Slot antenna. During his research, He has published 26 research papers in various reputed publishing houses like IEEE, Wiley, AEU, Hindawi and many more. Dr. Kumar has been served as a reviewer for many Journals like Wiley, Elsevier, and PIERS, etc. and also worked as a reviewer for ICICS-2016 for the track of Antenna Design. 